\title{
The Role of Memory Reactivation during Wakefulness and Sleep in Determining Which Memories Endure
}

\author{
Delphine Oudiette, James W. Antony, Jessica D. Creery, and Ken A. Paller \\ Northwestern University, Evanston, Illinois 60208-2710
}

Consolidation makes it possible for memories of our daily experiences to be stored in an enduring way. We propose that memory consolidation depends on the covert reactivation of previously learned material both during sleep and wakefulness. Here we tested whether the operation of covert memory reactivation influences the fundamental selectivity of memory storage- of all the events we experience each day, which will be retained and which forgotten? We systematically manipulated the value of information learned by 60 young subjects; they learned 72 object-location associations while hearing characteristic object sounds, and a number on each object indicated the reward value that could potentially be earned during a future memory test. Recall accuracy declined to a greater extent for low-value than for high-value associations after either a $90 \mathrm{~min}$ nap or a $90 \mathrm{~min}$ wake interval. Yet, via targeted memory reactivation of half of the low-value associations using the corresponding sounds, these memories were rescued from forgetting. Only cued associations were rescued when sounds were applied during wakefulness, whereas the entire set of low-value associations was rescued from forgetting when the manipulation occurred during sleep. The benefits accrued from presenting corresponding sounds show that covert reactivation is a major factor determining the selectivity of memory consolidation in these circumstances. By extension, covert reactivation may determine the ultimate fate of our memories, though wake and sleep reactivation might play distinct roles in this process, the former helping to strengthen individual, salient memories, and the latter strengthening, while also linking, categorically related memories together.

\section{Introduction}

The reactivation of stored information is hypothesized to support systems consolidation, a prolonged process whereby some newly acquired memories stabilize (O'Neill et al., 2010; Carr et al., 2011). In rats, specific patterns of neural activity during waking were spontaneously replayed during subsequent sleep (Wilson and McNaughton, 1994) and the amount of reactivation predicted memory performance (Dupret et al., 2010). In humans, behavioral replay of a trained motor sequence was observed during a sleepwalking episode (Oudiette et al., 2011). Also, brain activation linked to motor skills and spatial navigation was recapitulated during sleep, and levels of this activation predicted memory improvement (Maquet et al., 2000; Peigneux et al., 2004). However, a direct demonstration that memory reactivation mediates consolidation is lacking. Nevertheless, this hypothesized role of reactivation as a pivotal mechanism of sleep-dependent memory consolidation has come to predominate (Maquet, 2001; Stickgold, 2005; Diekelmann and Born, 2010; Saletin and Walker,

Received Nov. 28, 2012; revised Feb. 26, 2013; accepted March 11, 2013.

Author contributions: D.O., J.W.A., and K.A.P. designed research; D.0. performed research; J.W.A. and J.C.C. contributed unpublished reagents/analytic tools; D.0. analyzed data; D.0. and K.A.P. wrote the paper.

This work was based on work supported by National Science Foundation Grant BCS1025697. D.0. is a beneficiary of a postdoctoral Grant from the AXA Research Fund and a laureate of the Young Researcher Prize from the Bettencourt Schueller Foundation.

The authors declare no competing financial interests.

Correspondence should be addressed to Dr. Ken Paller, Northwestern University, 2029 Sheridan Road, Evanston, IL 60208-2710. E-mail: kap@northwestern.edu.

DOI:10.1523/JNEUROSCI.5497-12.2013

Copyright $\odot 2013$ the authors $\quad 0270-6474 / 13 / 336672-07 \$ 15.00 / 0$
2012). Here, we investigated whether reactivation contributes to the selectivity of consolidation that may ultimately determine what can or cannot be remembered.

Which among a large supply of available memories are replayed during sleep? One possibility is that replay is random and equally likely for all recently acquired memories. Alternatively, sleep may allow for preferential consolidation. In rats, some evidence implicates preferential replay of rewarded information (Lansink et al., 2008, 2009) and of episodes involving a critical choice-point (Peyrache et al., 2009). Preferential sleep consolidation has not been directly demonstrated in humans, but there is some indirect support. Emotionally salient stimuli ( $\mathrm{Hu}$ et al., 2006; Sterpenich et al., 2009), intention to remember (Wilhelm et al., 2011; van Dongen et al., 2012), and anticipation of a future reward for correct remembering (Fischer and Born, 2009) all enhanced the benefit of sleep. Additionally, after explicit instructions to encode some items and forget others, sleep consolidation was biased toward to-be-remembered items (Fischer et al., 2011; Rauchs et al., 2011; Saletin et al., 2011). These studies suggest that sleep-dependent memory consolidation entails selectivity, but reactivation may not be responsible. As suggested in the synaptichomeostasis hypothesis, selectivity may be an indirect consequence of global downscaling of synaptic connectivity (Tononi and Cirelli, 2006).

Selective consolidation may transpire during waking as well as sleep (Marr, 1971; Paller, 1997, 2009). Waking reactivation could foster consolidation, especially for experiences associated with reward (Foster and Wilson, 2006; Karlsson and Frank, 2009; Singer and Frank, 2009; Dupret et al., 2010; Jadhav et al., 2012). 
Information is not destined to be remembered because it is important or forgotten because it is unimportant. Rather, we propose that important information tends to be replayed, and replay tends to forestall forgetting. In four experiments, we monitored memory decline as a function of potential reward value. We also attempted to reactivate memories using auditory cues associated with learning (Oudiette and Paller, 2013), reasoning that if sleep reactivation is critical for consolidation selectivity, then targeted memory reactivation would rescue low-value memories from forgetting. We asked whether sleep has a unique role in selective memory consolidation by using the same procedures during sleep and wakefulness.

\section{Materials and Methods}

Subjects. Sixty healthy young adults were compensated for their participation at a rate of $\$ 10 / \mathrm{h}$. Data from additional subjects were excluded due to poor learning ( $<50 \%$ of the items correctly remembered after encoding, $n=5)$, insufficient sleep duration $(n=5)$, waking during sound presentation $(n=1)$, or sleeping while in the wake group $(n=1)$. All subjects reported that they did not have any sleep disorders and that they were not taking medications for any neurological conditions. Subjects were instructed not to nap and not to ingest caffeine during the day before the experiment. Subjects were assigned to one of four groups: Experiment $\mathrm{I}(n=15,5$ men, mean age $=20.5 \pm 4.2$ years $)$, Experiment II $(n=15,6$ men, mean age $=20.7 \pm 2.5$ years $)$, Experiment III $(n=15$, 6 men, mean age $=20.6 \pm 3.4$ years $)$, or Experiment IV $(n=15,7$ men, mean age $=21.1 \pm 2.9$ years). Experiments I and II were run concurrently with subjects randomly assigned to one of the two sleep groups. Experiments III and IV were then run in succession.

Design and procedure. Subjects were instructed to remember the unique locations of 72 objects on a screen. Each time an object was seen it was accompanied by a characteristic sound (e.g., dog + woof, bell + clang). To systematically bias this learning, a value number was superimposed on each object to indicate the potential future payoff for remembering its location. Half of the memories were low value and half were high value. Subjects were instructed to memorize object locations so as to maximize their financial reward (Fig. 1 details the experimental procedure).

Experiments I and II began with a learning phase between 11:00 A.M. and 3:00 P.M. Learning was followed by the application of electrodes for standard sleep EEG recording (see below). After this 45 min delay, memory was tested (see below for learning and testing procedures). Then, subjects reclined in a quiet, darkened room to sleep for $90 \mathrm{~min}$. Lowintensity white noise at $\sim 37 \mathrm{~dB}(\mathrm{~A})$ was present for the duration of the sleep period to dampen the influence of possible noise from outside the room and (for Experiment II) to embed the cues.

Object sounds were always presented during learning and testing. In Experiment I, no object sounds were presented during the nap. In Experiment II, 18 sounds associated with half of the low-value objects were presented during the nap. These sounds were chosen for each subject such that pre-nap recall accuracy was matched for cued and noncued low-value objects. All low-value objects were ranked as a function of pre-nap recall accuracy; sounds associated with even-ranked objects served as cues during sleep. Sounds were presented during slow-wave sleep except when no slow-wave sleep was observed after $45 \min (n=2$ in each experiment), in which case they were presented in non-rapid-eyemovement (NREM) stage 2 . Stimulation rate was one sound every $5 \mathrm{~s}$ with $\sim 1$ min between list repetitions. Stimulation was immediately stopped if EEG recordings showed any signs of micro-arousal or full awakening. To increase chances for replay, the list of sounds was repeated up to 10 times until slow-wave sleep ended. The nap period ended after $90 \mathrm{~min}$, except if the participant was in slow-wave sleep at this time (this occurred in only two participants, one in each sleep experiment). To reduce sleep inertia, a 10-15 min delay was included after the nap while the electrodes were removed and hair was cleaned. Spatial recall was then tested as in the pre-nap test.

In Experiments III and IV, the learning phase was the same, but afterward subjects stayed awake and EEG was not recorded. In Experiment
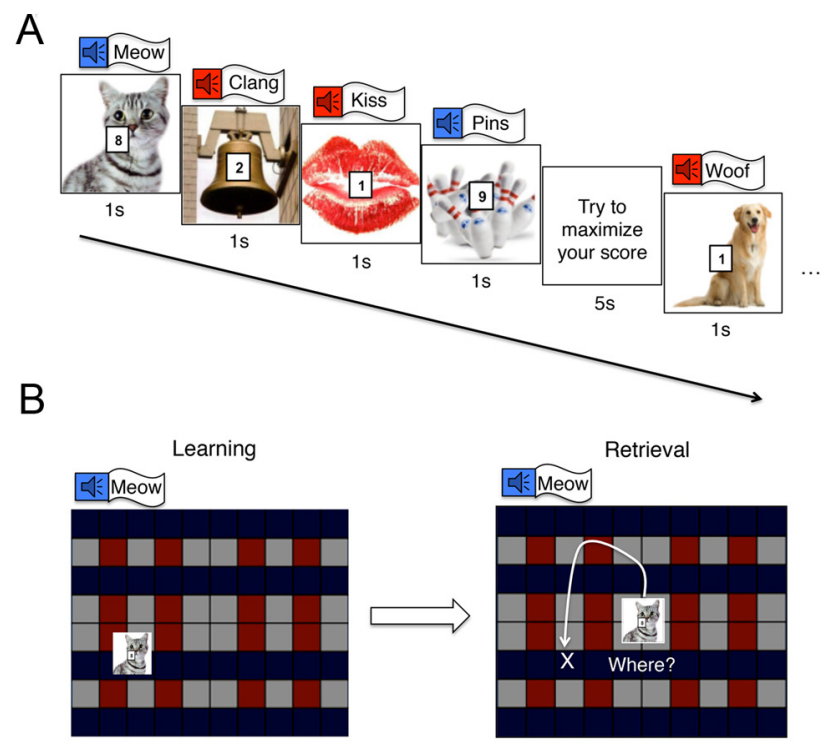

C
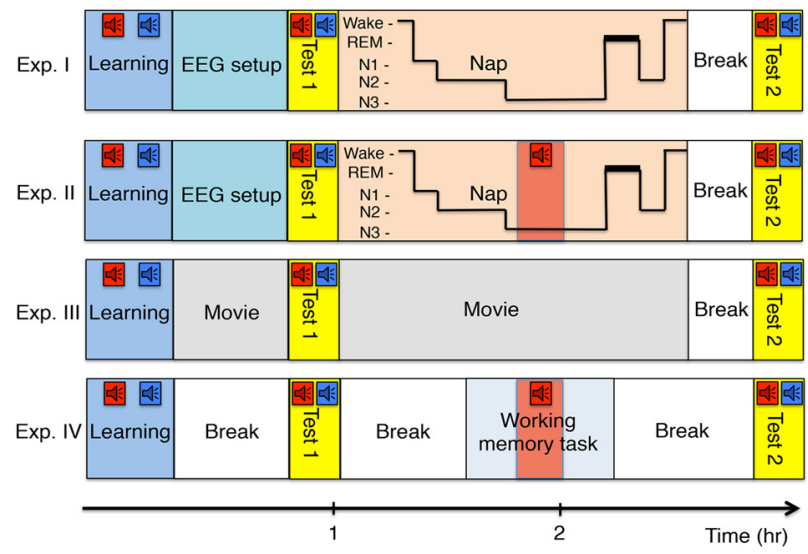

Figure 1. Experimental design. $\boldsymbol{A}$, Subjects learned object-location associations while hearing characteristic object sounds. A number on each object indicated its potential reward value (points to be awarded when the location was recalled during a future memory test, later converted to money). Instructions were to plan learning to maximize future reward. The block design depicted is explained in detail in Materials and Methods. All objects were superimposed on the grid (as shown in $\boldsymbol{B}$ ) during learning. $\boldsymbol{B}$, For recall testing, each object appeared at the center of the screen and the subject attempted to move it to the original location as accurately as possible. C, In Experiment I, subjects took a 90 min nap while continuous white noise was presented from a speaker. Experiment II was the same except that half of the sounds corresponding to low-value objects were played during slow-wave sleep at the same intensity as the continuous white noise. In Experiment III, subjects stayed awake between the two tests. In Experiment IV, half of the sounds corresponding to low-value objects were played while subjects stayed awake and performed a working-memory task.

III, subjects watched a movie (e.g., a documentary film about animals). At $30 \mathrm{~min}$, the movie was paused and spatial recall was tested. The movie then resumed for $90 \mathrm{~min}$. After a $5 \mathrm{~min}$ break, spatial recall was tested again. The sounds associated with the objects were presented during learning and testing but not during the interval between the two tests. The timing of the two tests corresponded to that of the pre-nap and post-nap tests in Experiments I and II. In Experiment IV, subjects were engaged in a difficult working-memory task for $30 \mathrm{~min}, 1 \mathrm{~h}$ after the first test (corresponding approximately to the time when sounds were applied in the sleep group). In the working-memory task, random numbers between 1 and 9 were displayed at a fast speed on the screen (numbers appeared for $400 \mathrm{~ms}$ at a rate of one every $900 \mathrm{~ms}$ ). Subjects compared each number with the preceding one and pressed one button if they were both even or both odd, and the other button if one number was odd and the other even. For example, if the first number was 3 and then a 7 
appeared, the subject had to press left; if a 6 appeared next, the subject had to press right. After a 2 min practice run, subjects performed three $7.5 \mathrm{~min}$ runs. White noise was played while subjects completed this task, with embedded sounds corresponding to half of the low-value objects beginning $1.5 \mathrm{~min}$ after the start of the second run. Subjects were told to maintain their focus on the task as much as possible, and they were given feedback at the end of each run to reinforce this focus. Because this task required a high level of attention, subjects were not able to focus on the sounds. This manipulation attempted to mimic the unconscious perception of the sounds during sleep. Before and after the working-memory task, subjects were allowed to engage in a quiet activity (e.g., read a book or play a game). They were tested twice for the object-location task and the timing of these tests was the same as in all other experiments.

Memory task. During the learning phase, subjects attempted to associate each of 72 object images with a location on a grid-like computer screen (Fig. 1). Locations were randomly determined for each object and each participant, such that each object could appear anywhere on the screen. Each object was always seen in conjunction with its characteristic sound delivered over a speaker. Numbers were randomly assigned to each object $(1,2,8$, or 9 , equally distributed). This number was superimposed on the object and indicated the value of a subsequent monetary reward for correctly remembering an object's location (reward for correct recall $=\$ 0.02 \times$ value). This procedure simulates the fact that things we learn each day vary in their future value. The directed forgetting manipulation used in prior studies (Fischer et al., 2011; Rauchs et al., 2011; Saletin et al., 2011), in contrast, requires an intention to forget some information, which is arguably less naturalistic than the directed remembering used here.

Objects were displayed in three blocks of 24 objects. Each block included six miniblocks of four objects including one of each value $(1,2,8$, 9). Each object appeared for $1000 \mathrm{~ms}$ in a random order. After each miniblock, "Try to maximize your score" was displayed for $5000 \mathrm{~ms}$. During this period, participants were invited to mentally rehearse the two high-value object locations. Additional miniblocks followed until $24 \mathrm{ob}-$ jects were seen. Then the set of objects was repeated an additional two times. For these repetitions, the 24 objects were randomly assigned to trials in a different way, but always with the same values and with the restriction that all four values were represented in each miniblock. A short break was allowed between blocks.

For testing, a random sequence of the 72 objects was presented. Each object (along with its value) appeared at the center of the screen while its sound played, and subjects attempted to drag the object to the original location with a mouse. Subjects received no feedback on recall accuracy during the test. At the end of the test, they were informed of their final score and their monetary reward. To achieve correct recall and earn the corresponding reward defined by object value, the participant had to place the object within 150 pixels $(5.4 \mathrm{~cm}$ ) of the original location (as in the study by Rudoy et al., 2009). This testing procedure was used both before the nap (Test 1) and after the nap (Test 2). In each test objects appeared in a different random order.

Sleep recordings. EEG was measured using tin electrodes placed on the scalp at 21 standard locations from the 10-20 system (Cz, C3, C4, Fpz, Fp1, Fp2, Fz, F3, F4, F7, F8, Pz, P3, P4, T3, T4, T5, T6, Oz, O1, O2), referenced to average mastoids, along with two electrooculogram (EOG) channels and one chin electromyogram (EMG) channel. Signals were sampled at $250 \mathrm{~Hz}$ and filtered with a bandpass of $0.5-30 \mathrm{~Hz}$ (EEG and EOG) or $10-70 \mathrm{~Hz}$ (EMG). Sleep staging was conducted offline using standard criteria.

EEG spectral analyses were conducted following artifact removal based on visual inspection. Fast Fourier transform was applied using a Hanning function and $5 \mathrm{~s}$ intervals, yielding a frequency resolution of 0.2 $\mathrm{Hz}$. Individual mean power was computed separately for the delta band $(0.5-4 \mathrm{~Hz})$ and for slow $(0.5-1 \mathrm{~Hz})$ and fast $(1-4 \mathrm{~Hz})$ portions of the delta band. Individual mean power was computed for six sets of regions: frontopolar (average of Fpz, Fp1, Fp2), frontal (F3, F4, Fz, F7, F8), central (C3, Cz, C4), parietal (P3, P4, Pz), temporal (T3, T4, T5, T6), and occipital $(\mathrm{O} 1, \mathrm{Oz}, \mathrm{O} 2)$.

Statistical analysis. Given that our predictions concerned the possibility of preferential consolidation during sleep, analyses were restricted to
Table 1. Behavioral performance in recall Test 1

\begin{tabular}{lll}
\hline Experimental condition & High-value objects & Low-value objects \\
\hline $\begin{array}{l}\text { Experiment I, no sounds during sleep } \\
\quad \text { Number correct }\end{array}$ & $30.1 \pm 1.2$ & $23.1 \pm 1.7$ \\
$\quad$ Recall error & $2.22 \pm 0.08$ & $2.60 \pm 0.1$ \\
$\begin{array}{l}\text { Experiment II, sounds during sleep } \\
\quad \text { Number correct }\end{array}$ & $30.8 \pm 1.1$ & $25.9 \pm 1.4$ \\
$\quad$ Recall error & $2.30 \pm 0.1$ & $2.45 \pm 0.1$ \\
$\begin{array}{l}\text { Experiment III, no sounds during wakefulness } \\
\quad \text { Number correct }\end{array}$ & $30.1 \pm 1$ & $21.6 \pm 2.1$ \\
$\quad$ Recall error & $2.27 \pm 0.1$ & $2.55 \pm 0.1$ \\
Experiment IV, sounds during wakefulness & & \\
$\quad$ Number correct & $30.7 \pm 1.4$ & $23.6 \pm 1.6$ \\
$\quad$ Recall error & $2.16 \pm 0.12$ & $2.42 \pm 0.10$ \\
\hline
\end{tabular}

Values are mean \pm SEM.

associations that were accurately memorized before sleep. Accordingly, behavioral analyses excluded data for any object placed $>150$ pixels from the original location at Test 1 . Thus, reported results concerned objects that were adequately encoded.

Data were analyzed using a three-way ANOVA with two withinsubject factors (low vs high value, Test 1 vs 2 ) and one across-subject factor (sounds vs no sounds). Where appropriate, conditions were further analyzed using separate ANOVAs and paired-sample $t$ tests. Sleep measures in Experiments I and II were compared using unpaired $t$ tests. All tests were two-tailed. Correlations between delta EEG power at frontal locations and behavioral performances were performed using a Pearson correlation test.

\section{Results}

\section{High-value information was learned better than} low-value information

As expected, recall tested $45 \mathrm{~min}$ after learning was more accurate for high-value than low-value objects in the four groups of subjects, measured either by the number of correct locations recalled or relative to the exact location, as shown in Table 1 . These results validated our directed-remembering design, which aimed to bias encoding as a function of value. Across all experiments, more high-value than low-value objects were correctly recalled $(30.5 \pm 0.6$ vs $23.6 \pm 0.9$, respectively; $\left.F_{(1,56)}=60.6, p<0.0001\right)$. Likewise, the recall error was smaller for high-value than for low-value objects $\left(2.22 \pm 0.08\right.$ vs $2.60 \pm 0.11$, respectively; $\left.F_{(1,56)}=27.2, p<0.0001\right)$. Neither effect varied across experiment $\left(F_{(3,56)}=0.70, p=0.56\right.$; $\left.F_{(3,56)}=0.84, p=0.48\right)$.

\section{The fate of stored information after sleep depended on the value accorded to later remembering}

In Experiment I, we examined whether change in recall accuracy after a 90 min interval of sleep differed as a function of value. When recall was tested after sleep, accuracy declined to a greater extent for low-value than for high-value objects (Figure 2A) (differential change in error for low minus high value $=1.05 \pm 0.15$ $\mathrm{cm}$, test session $\times$ value; $\left.F_{(1,14)}=11.6, p=0.004\right)$.

\section{Targeted reactivation during sleep rescued low-value information from forgetting}

Whereas Experiment I showed that items tagged as important during learning were advantaged over the interval with sleep, in Experiment II we sought to determine whether we could encourage sleep reactivation for low-value memories using external cues during slow-wave sleep. After the nap, no subject reported hearing the sounds, even though they were presented repeatedly (mean, 5.7 repetitions; range, 1-10). Change in memory across the nap did not differ as a function of value (Figure $2 B$ ) (differ- 

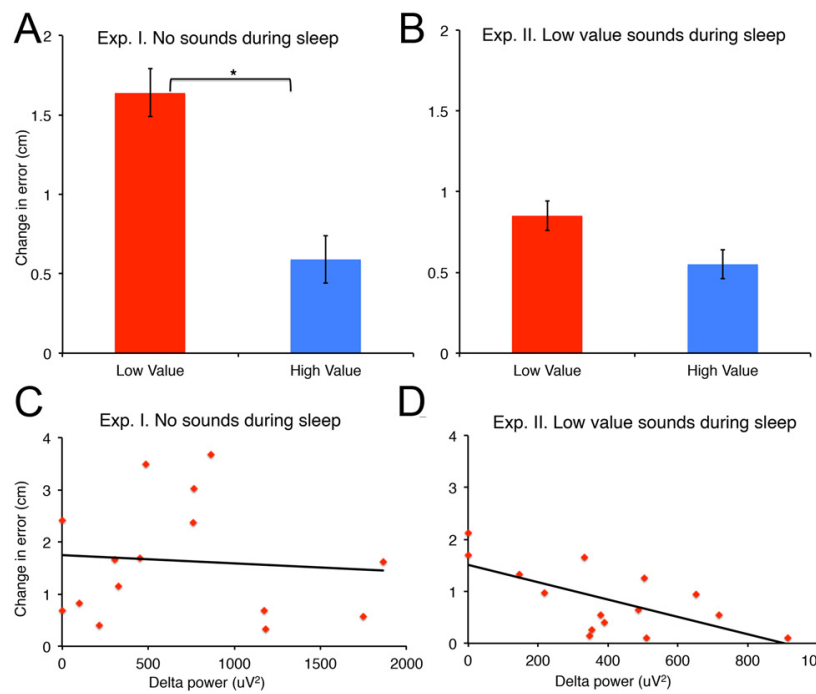

D

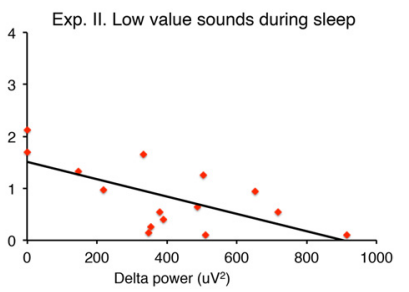

Figure 2. Memory performance across a nap. $\boldsymbol{A}, \boldsymbol{B}$, Memory change scores were computed as the difference in recall error between the two tests. In general, individuals placed objects less accurately at Test 2 than at Test 1 . This decline was worse for low-value objects (in red) compared with high-value objects (in blue) in Experiment I but not in Experiment Il. Error bars depict SEM after correcting for across-subject variability, such that these measures of variability correspond to the error term for the within-subjects contrast as a function of value. $C, D$, In Experiment II but not in Experiment I, memory accuracy for low-value objects was correlated with delta power at frontopolar midline scalp locations during slow-wave sleep. *Indicates significant difference between conditions.

ential change in error for low minus high value $=0.30 \pm 0.09 \mathrm{~cm}$, test session $\times$ value; $\left.F_{(1,14)}=2.4, p=0.2\right)$. A direct comparison between the two groups to which subjects were randomly assigned (Experiment I vs II) confirmed that retention of low-value objects after the nap was modified depending on whether or not cues were applied during the nap (test session $\times$ value $\times$ experiment; $\left.F_{(1,28)}=5.0, p=0.03\right)$. Of note, the two subjects who received cues during stage 2 instead of slow-wave sleep exhibited the smallest benefit over the sleep interval.

\section{Auditory cues applied during sleep acted as contextual cues for the low-value category}

We examined whether the external cues applied during sleep specifically reinforced their corresponding individual memories or benefitted all low-value objects more generally. In Experiment II, accuracy was matched after the final stage of learning for the two sets of low-value objects assigned to the cued and uncued conditions. Accuracy was thus very similar after learning (error $=2.47 \pm 0.12$ for cued and $2.41 \pm 0.12$ for uncued; $t_{(14)}=1.0, p=0.3$ ). After sleep, accuracy also did not differ significantly between the two types of low-value information (Figure $3 A$ ) (change in error $=0.70 \pm 0.22$ for cued and $0.99 \pm 0.22 \mathrm{~cm}$ for uncued; $\left.t_{(14)}=1.0, p=0.3\right)$. In other words, the sounds for half of the low-value objects appeared to function as cues to the whole category of low-value objects.

\section{The intensity of the cueing benefit was correlated with slow-wave sleep characteristics}

Table 2 shows sleep measures for Experiment I and II. The general architecture of sleep was not different across experiment. Because slow waves are hypothesized to orchestrate hippocampalneocortical interactions and memory reactivation during sleep (Mölle and Born, 2011), we performed spectral analysis to determine whether specific delta power variations were associated with the differential memory evolution in the two experiments.

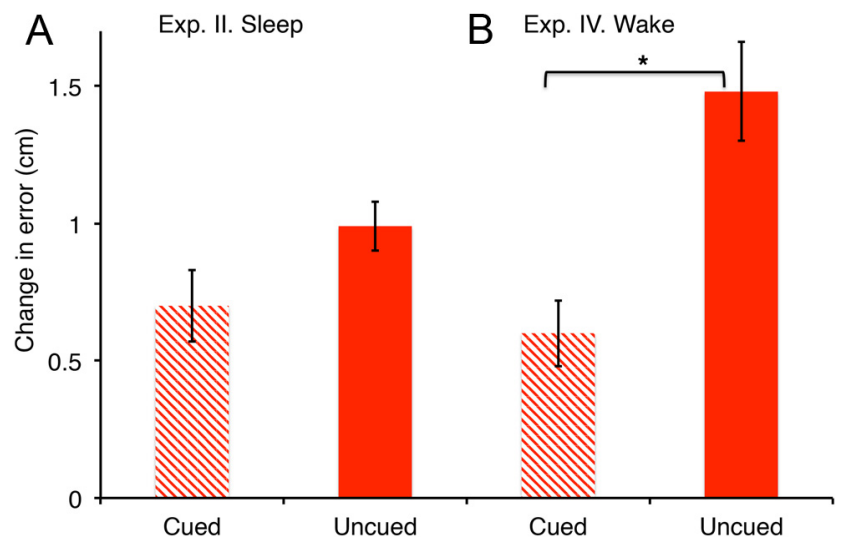

Figure 3. Memory performance for cued versus uncued low-value associations. Memory change scores were computed as the difference in recall error between the two tests. At retest, low-value associations that were not cued during sleep benefitted to the same extent as those that were cued ( $\boldsymbol{A}$, Experiment II). In contrast, when sounds were applied during wakefulness, cued associations benefited more than uncued associations ( $\boldsymbol{B}$, Experiment IV). Error bars depict SEM after correcting for across-subject variability, such that these measures of variability correspond to the error term for the within-subjects contrast as a function of cuing.

Table 2. Sleep measures in Experiments I and II

\begin{tabular}{lrrr}
\hline Measure & Experiment I & Experiment II & $p$ \\
\hline Sleep onset latency & $9.6 \pm 1.5$ & $10.4 \pm 1.2$ & 0.67 \\
Total sleep time & $65.8 \pm 5.6$ & $64.9 \pm 3.1$ & 0.88 \\
Wake after sleep onset & $14.1 \pm 3.8$ & $13.1 \pm 2.3$ & 0.82 \\
Duration N1 (non-REM stage 1) & $5.2 \pm 0.9$ & $5.1 \pm 1.0$ & 0.92 \\
Duration N2 (non-REM stage 2) & $28.1 \pm 3.9$ & $32.6 \pm 2.8$ & 0.36 \\
Duration N3 (slow-wave sleep) & $22.3 \pm 4.8$ & $20.5 \pm 3.3$ & 0.77 \\
Duration REM (REM sleep) & $10.2 \pm 2.7$ & $6.6 \pm 2.5$ & 0.34 \\
\hline
\end{tabular}

Values are $\min \pm$ SEM.

In Experiment II, change in recall error for low-value associations across the nap period was negatively correlated with measures of slow-wave sleep (Fig. 2D) (duration of slow-wave sleep, $r=-0.54, p=0.04$; delta power during this stage at the frontopolar region, where it is maximal, $r=-0.65, p=0.007)$. Further analyses showed that the recall correlations in Experiment II were observed for both frontopolar and frontal delta power, and whether the full delta band $(0.5-4 \mathrm{~Hz})$, the slow oscillation portion $(0.5-1 \mathrm{~Hz})$ or the remaining faster delta power $(1-4 \mathrm{~Hz})$ were considered (frontopolar delta: $r=-0.65, p=0.007$, frontal delta: $r=-0.63, p=0.011$; frontopolar slow oscillations: $r=$ $-0.56, p=0.027$, frontal slow oscillations: $r=-0.61, p=0.014$; frontopolar faster delta: $r=-0.61, p=0.014$, frontal faster delta: $r=-0.59, p=0.018$ ). The correlations were nonsignificant for other EEG locations (aside for a trend at the temporal location with the full delta band, $r=-0.54, p=0.036$ ). Of note, correlations with delta power and recall change scores were restricted to slow-wave sleep and were not observed for EEG data from the full set of NREM sleep intervals.

Interestingly, none of these correlations were observed in Experiment I, when subjects received no cues (Fig. $2 C)(r=0.09$, $p=0.76 ; r=-0.08, p=0.77$, respectively for duration and delta power in slow-wave sleep at the frontopolar region). Delta power during slow-wave sleep did not correlate either with memory performance for the high-value items (Experiment I, $r=-0.19$, $p=0.49$; Experiment II, $r=-0.37, p=0.17)$.

Furthermore, because a previous study reported that rapideye-movement (REM) sleep might play a role in directed forgetting (Fischer et al., 2011), we determined whether REM sleep 

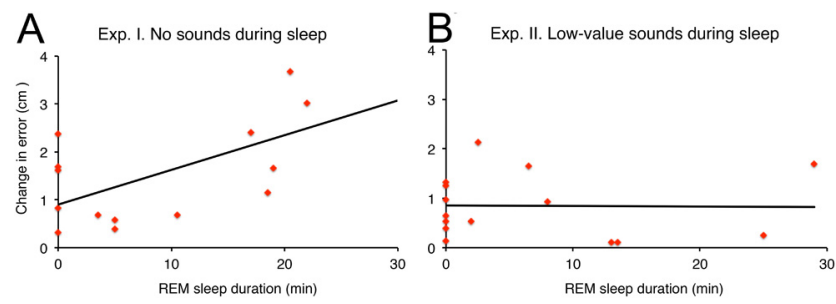

Figure 4. Correlation between REM sleep duration and memory performance. In Experiment I $(\boldsymbol{A})$ but not in Experiment II $(\boldsymbol{B})$, memory accuracy for low-value objects was correlated with REM sleep duration.
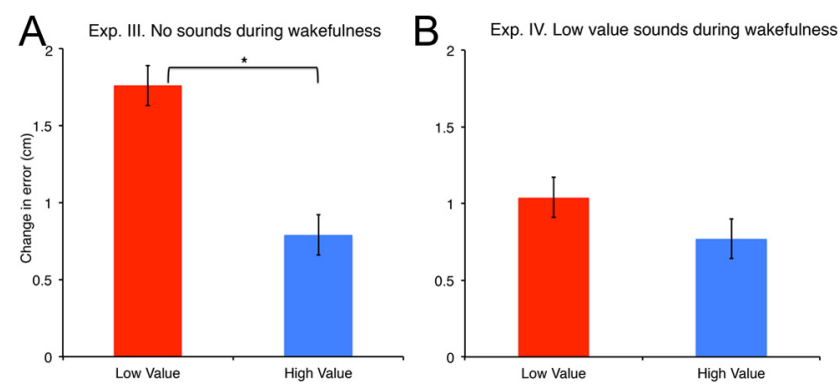

Figure 5. Memory performance across an interval of wakefulness. $A, B$, Memory change scores were computed as the difference in recall error between the two tests. In general, individuals placed objects less accurately at Test 2 than at Test 1 . This decline was worse for lowvalue objects compared with high-value objects after a period of wakefulness without sounds (Experiment III), but not after a period of wakefulness with sounds (Experiment IV). Error bars depict SEM after correcting for across-subject variability, such that these measures of variability correspond to the error term for the within-subjects contrast as a function of value.

duration was correlated with memory changes. As shown in Figure 4, the decline in memory for low-value objects (measured by the change in error) correlated with REM sleep duration in Experiment I $(r=0.67, p=0.006)$ but not in Experiment II $(r=$ $0.02, p=0.95)$. Of note, the association between REM sleep and poor performance in Experiment I could not be explained as an indirect reflection of a reduction of slow-wave sleep, because there was no apparent impact of slow-wave sleep duration on REM sleep duration $(r=-0.02, p=0.95)$.

\section{Selective processes were not exclusive to sleep}

In Experiment III, we tested whether selective memory processing was restricted to sleep using the same basic design as in Experiment I except with a period of wakefulness in place of the nap. At the final test, memory declined to a significantly greater extent for low-value compared with high-value objects (Figure $5 A$ ) (differential change in error for low minus high value $=0.97 \pm 0.13$ $\mathrm{cm}$, test session $\times$ value; $\left.F_{(1,14)}=14.0, p=0.002\right)$.

This preferential forgetting of low-value associations was not different from that in Experiment I (test session $\times$ value $\times$ experiment; $\left.F_{(1,28)}=0.05, p=0.8\right)$, but was different from the pattern of forgetting in Experiment II (test session $\times$ value $\times$ experiment; $\left.F_{(1,28)}=5.2, p=0.03\right)$. However, interpretations of these cross-experiment analyses must be made with caution because Experiment III was conducted last. Although comparable subject recruitment procedures were used, unintended differences between subjects in the wake and sleep experiments cannot be ruled out. Yet, when targeted memory reactivation was not used, results between sleep (Fig. 1A) and wake (Fig. 5A) were remarkably similar.

\section{Targeted reactivation during wake rescued low-value memories from forgetting}

To test whether the cueing effect observed in Experiment II was due to unique properties of sleep, we ran another group of subjects who received sounds for half of the low-value objects during a period of wakefulness (Experiment IV). After completing the working-memory task, only five subjects reported hearing sounds related to the previous learning, and they were unable to say which sounds. The remaining subjects reported hearing no sounds at all $(n=1)$, some sound attributed to noise from another experimental room $(n=2)$, a "bip" sound without significance $(n=2)$, or a buzzing sound interpreted as feedback for the working-memory task $(n=5)$. Overall, the sounds did not seem to trigger intentional rehearsal of object-location associations when applied in this paradigm during wake, presumably due to the high demands of the working-memory task. Change in memory between the first and second test did not differ as a function of value when the sounds were applied during wake (Figure $5 B$ ) (differential change in error for low minus high value $=0.27 \pm$ $0.13 \mathrm{~cm}$, test session $\times$ value; $\left.F_{(1,14)}=1.9, p=0.19\right)$.

A direct comparison of the change in error between the two groups of awake participants (Experiment III, without sounds, and Experiment IV, with sounds) failed to reach significance (test session $\times$ value $\times$ experiment; $F_{(1,28)}=2.4, p=0.13$ ). However, the latter comparison does not take into account the fact that cues were presented for half of the low-value associations and not for the remaining associations. A direct comparison of the differential error change excluding low-value associations that were not cued in Experiment IV yielded a significant difference between the two experiments (test session $\times$ value $\times$ experiment; $F_{(1,28)}=9.3, p=0.005$ ).

\section{The cueing effect during wake was restricted to low-value items that were cued}

As in Experiment II, accuracy was matched after the final stage of learning for two sets of low-value objects assigned to the cued and uncued conditions. Accuracy was thus very similar after learning (error $=2.40 \pm 0.10 \mathrm{~cm}$ for cued and $2.43 \pm 0.11 \mathrm{~cm}$ for uncued; $\left.t_{(14)}=0.43, p=0.7\right)$. In contrast with cueing during sleep, auditory cues during wake specifically reinforced their corresponding individual low-value memories (change in error $=0.60 \pm 0.14$ $\mathrm{cm}$ for cued vs $1.48 \pm 0.36 \mathrm{~cm}$ for uncued objects; $t_{(14)}=3.1, p=$ 0.008 ) (Figure $3 B$ ). A direct comparison of the change in error for the cued versus uncued low-value associations between the sleep (Experiment II) and wake group (Experiment IV) showed a trend (test session $\times$ cue $\times$ experiment; $F_{(1,28)}=3.4, p=0.078$ ).

\section{Discussion}

Our first experiment showed that the reward value accorded to stored information determined sleep consolidation, in that a relative advantage was produced for high-value information. The claim that sleep consolidation is biased toward to-be-remembered items (Fischer et al., 2011; Rauchs et al., 2011; Saletin et al., 2011) was thus extended to a novel reward-based paradigm with directed remembering.

Our second experiment showed that cues to reactivate lowvalue memories rescued them from forgetting. The memory benefit from this targeted memory reactivation (for review of this procedure, see Oudiette and Paller, 2013) was greatest in individuals with robust slow waves, as in related studies (Huber et al., 2004; Marshall et al., 2006) and in keeping with a link between spatial reactivation and slow-wave sleep (Wilson and McNaughton, 1994; Peigneux et al., 2004; Bendor and Wilson, 2012). Interestingly, we found this slow-wave/memory correla- 
tion for low-value associations in Experiment II but not in Experiment I (when the memory decline was greater). Together, these findings strongly suggest that sleep replay is pivotal for determining the selectivity of memory storage, and that it transpires without our awareness while we are asleep.

We also found that the decline in memory for low-value associations was correlated with REM sleep duration in Experiment I. In contrast, other studies associated memory benefits with REM sleep (Karni et al., 1994; Nishida et al., 2009; Fischer et al., 2011). Diekelmann and Born (2010) proposed that REM sleep promotes synaptic consolidation, strengthening memories that undergo reorganization during prior slow-wave sleep. However, our data do not support a beneficial effect of REM sleep, but rather suggest an active role for REM sleep in weakening memories of low value (Crick and Mitchison, 1983). It is possible that REM sleep promotes both forgetting and remembering. We speculate that cueing in Experiment II triggered the reactivation of low-value information in slow-wave sleep; thereby stabilizing memories that otherwise would tend to be erased in the subsequent REM sleep period. Further investigations are needed to determine the intriguing role of REM sleep in the selection or competition among memories.

In our previous studies (Rudoy et al., 2009; Antony et al., 2012), characteristic sounds were thought to specifically trigger memory reactivation, such that accuracy was superior for cued compared with uncued information. In Experiment II of this study, half of the low-value objects were cued but all of the lowvalue objects benefitted. One critical feature of this study may have been that subjects categorized objects into those of high and low value. Subjects were compelled to categorize due to the repeated grouping of two high-value and two low-value objects, each time followed by an interval when subjects preferentially rehearsed high-value information to maximize their score. Presumably, sleep cues for low-value objects triggered reactivation of the whole set of low-value objects, which parallels the contextual effects found with odor cues in other memory paradigms (Rasch et al., 2007; Diekelmann et al., 2011).

In Experiment III, low-value associations were preferentially forgotten after an interval of wake, just as after an interval of sleep. One could be surprised by this result considering that many studies showed better memory after sleep than after wakefulness (Diekelmann and Born, 2010; Saletin and Walker, 2012). In particular, if important memories are actively reactivated during sleep, one might expect better memory for high-value associations after sleep compared with after wake (Saletin et al., 2011). On the other hand, in a study combining fMRI with directed forgetting, Rauchs et al. (2011) found that recognition performance for to-be-remembered items after a delay was the same in subjects who slept and subjects who were sleep-deprived, whereas only those who slept showed greater hippocampal activity for to-be-remembered hits compared with misses. Still, we cannot rule out the possibility that sleep in our paradigm produced a memory benefit that was too small relative to across-subject memory variability; either a larger number of subjects or a more sensitive memory test may have revealed significant effects. Also, our design comprised low interference compared with that in other studies with longer periods of wake or interference manipulations to reveal memory benefits for sleep compared with waking (Ellenbogen et al., 2009; Diekelmann et al., 2011). Although there were no signs of between-group alertness differences, it is possible that participants in the sleep groups experienced some residual sleep inertia during memory testing, undermining a potential benefit of sleep compared with wakefulness. A study with final testing after a longer delay would allow this possibility to be evaluated.
Alternatively, and particularly in the context of rewarded learning, wakefulness might contribute to the consolidation of salient memories. Indeed, Singer and Frank (2009) showed that rewarded outcomes enhanced waking reactivation of the paths associated with the reward location during learning in rats. Furthermore, the amount of reactivation of goal-related patterns predicted later memory performance whether reactivation was during the acquisition phase or the subsequent rest phase, suggesting that both online and offline reactivation can strengthen memory (Dupret et al., 2010). Consonant with this notion, targeted reactivation of low-value associations in Experiment IV was sufficient to make low-value and high-value associations appear equivalently strong. This effect is particularly remarkable because the cues applied during wake did not necessarily lead to conscious access of the corresponding information; the high attentional demands of the working-memory task caused participants to focus on visual information instead of sounds, such that they claimed to have been unaware of the connection between the sounds and previous learning. Consequently, it is likely that subjects rarely rehearsed object locations in an active manner, although direct evidence on this point is lacking.

Benefits of cueing during wake apparently depend on the procedure. In our previous object-location study, sounds presented during a post-learning wake interval did not reliably influence recall accuracy, but some subjects did benefit (Rudoy et al., 2009). There is no doubt that cues are effective when they lead people to rehearse learned information (Karpicke and Roediger, 2008). In another study that compared cues during waking and sleep, Diekelmann et al. (2011) used an interference task just after odorcued reactivation and found that cues during wakefulness weakened memory and cues during sleep strengthened memory. An alternative explanation for the former finding, however, is that the odor during wakefulness could have exacerbated interference by blending together the two learning intervals. Because of the long interval before the interference task in the condition of wakefulness without odor cues, initial learning and interference learning could more easily be mentally segregated. In this study, we speculate that the expectation of reward boosted the efficiency of cueing in both sleep and wake conditions. Further studies are needed to assess potential interactions among sleep cueing, reward contingencies, interference, and other relevant factors.

The finding that cueing benefited all low-value associations in the sleep group, whereas it benefitted only cued associations in the wake group, suggests that sound-cued processing differs as a function of state. Karlsson and Frank (2009) argued that wake replay in rats provided a higher-fidelity recapitulation of past experiences than replay during sleep. If the same generalization holds in humans, the specificity of cueing during wake makes sense. In addition, sleep replay may promote generalization and abstraction, as many observations suggest. For example, subjects more efficiently extracted the meaning of Chinese characters after a nap than after wake (Lau et al., 2011), and infants who napped were better at generalizing an abstract rule in an artificial language (Gomez et al., 2006). Similarly, after sleep subjects were twice as likely to discover a hidden rule (Wagner et al., 2004), improve in a probabilistic category-learning task (Djonlagic et al., 2009), or abstract statistical patterns (Durrant et al., 2011). Targeted reactivation during sleep may thus facilitate the reorganization of discrete memory traces into flexible relational networks (i.e., a constellation of object locations linked by their lowvalue characteristic), and ultimately reinforce memory for the entire domain.

Given that a person's stockpile of memories contributes in a major way to defining the individual and his or her place in the 
world, the mystery of why some memories fade while others endure has profound implications. Here, we showed that both sleep and wake reactivation are operative in the seemingly arbitrary nature of memory consolidation. We propose the following model for the systematic selectivity of memory consolidation, and call for further experimental validation of these speculations. First, when new information is acquired it is subject to the possibility of special treatment. Multiple factors at the time of encoding or subsequently (e.g., attention, intention, emotion, or repeated encounters) can lead some information to be tagged as potentially relevant for the future. During off-line periods of wakefulness and sleep, these valuable memories tend to be reactivated, perhaps via the activation of high-level associations and goals, thus improving memory storage and determining the ultimate destiny of memories. Memories are less likely to be forgotten the more often they are reactivated. Whereas wake reactivation may contribute to strengthening individual memories, memory strengthening during sleep reactivation could also entail linking together useful combinations of interrelated memories.

\section{References}

Antony JW, Gobel EW, O’Hare JK, Reber PJ, Paller KA (2012) Cued memory reactivation during sleep influences skill learning. Nat Neurosci 15: 1114-1116. CrossRef Medline

Bendor D, Wilson MA (2012) Biasing the content of hippocampal replay during sleep. Nat Neurosci 15:1439-1444. CrossRef Medline

Carr MF, Jadhav SP, Frank LM (2011) Hippocampal replay in the awake state: a potential substrate for memory consolidation and retrieval. Nat Neurosci 14:147-153. CrossRef Medline

Crick F, Mitchison G (1983) The function of dream sleep. Nature 304:111114. CrossRef Medline

Diekelmann S, Born J (2010) The memory function of sleep. Nat Rev Neurosci 11:114-126. CrossRef Medline

Diekelmann S, Büchel C, Born J, Rasch B (2011) Labile or stable: opposing consequences for memory when reactivated during waking and sleep. Nat Neurosci 14:381-386. CrossRef Medline

Djonlagic I, Rosenfeld A, Shohamy D, Myers C, Gluck M, Stickgold R (2009) Sleep enhances category learning. Learn Mem 16:751-755. CrossRef Medline

Dupret D, O’Neill J, Pleydell-Bouverie B, Csicsvari J (2010) The reorganization and reactivation of hippocampal maps predict spatial memory performance. Nat Neurosci 13:995-1002. CrossRef Medline

Durrant SJ, Taylor C, Cairney S, Lewis PA (2011) Sleep-dependent consolidation of statistical learning. Neuropsychologia 49:1322-1331. CrossRef Medline

Ellenbogen JM, Hulbert JC, Jiang Y, Stickgold R (2009) The sleeping brain's influence on verbal memory: boosting resistance to interference. PLoS One 4:e4117. CrossRef Medline

Fischer S, Born J (2009) Anticipated reward enhances offline learning during sleep. J Exp Psychol Learn Mem Cogn 35:1586-1593. CrossRef Medline

Fischer S, Diekelmann S, Born J (2011) Sleep's role in the processing of unwanted memories. J Sleep Res 20:267-274. CrossRef Medline

Foster DJ, Wilson MA (2006) Reverse replay of behavioural sequences in hippocampal place cells during the awake state. Nature 440:680-683. CrossRef Medline

Gómez RL, Bootzin RR, Nadel L (2006) Naps promote abstraction in language-learning infants. Psychol Sci 17:670-674. CrossRef Medline

Hu P, Stylos-Allan M, Walker MP (2006) Sleep facilitates consolidation of emotional declarative memory. Psychol Sci 17:891-898. CrossRef Medline

Huber R, Ghilardi MF, Massimini M, Tononi G (2004) Local sleep and learning. Nature 430:78-81. CrossRef Medline

Jadhav SP, Kemere C, German PW, Frank LM (2012) Awake hippocampal sharp-wave ripples support spatial memory. Science 336:1454-1458. CrossRef Medline

Karlsson MP, Frank LM (2009) Awake replay of remote experiences in the hippocampus. Nat Neurosci 12:913-918. CrossRef Medline

Karni A, Tanne D, Rubenstein BS, Askenasy JJ, Sagi D (1994) Dependence on REM sleep of overnight improvement of a perceptual skill. Science 265:679-682. CrossRef Medline

Karpicke JD, Roediger HL 3rd (2008) The critical importance of retrieval for learning. Science 319:966-968. CrossRef Medline

Lansink CS, Goltstein PM, Lankelma JV, Joosten RN, McNaughton BL, Pennartz CM (2008) Preferential reactivation of motivationally relevant information in the ventral striatum. J Neurosci 28:6372-6382. CrossRef Medline

Lansink CS, Goltstein PM, Lankelma JV, McNaughton BL, Pennartz CM (2009) Hippocampus leads ventral striatum in replay of place-reward information. PLoS Biol 7:e1000173. CrossRef Medline

Lau H, Alger SE, Fishbein W (2011) Relational memory: a daytime nap facilitates the abstraction of general concepts. PLoS One 6:e27139. CrossRef Medline

Maquet P (2001) The role of sleep in learning and memory. Science 294: 1048-1052. CrossRef Medline

Maquet P, Laureys S, Peigneux P, Fuchs S, Petiau C, Phillips C, Aerts J, Del Fiore G, Degueldre C, Meulemans T, Luxen A, Franck G, Van Der Linden M, Smith C, Cleeremans A (2000) Experience-dependent changes in cerebral activation during human REM sleep. Nat Neurosci 3:831-836. CrossRef Medline

Marr D (1971) Simple memory: a theory for archicortex. Philos Trans R Soc Lond B Biol Sci 262:23-81. CrossRef Medline

Marshall L, Helgadóttir H, Mölle M, Born J (2006) Boosting slow oscillations during sleep potentiates memory. Nature 444:610-613. CrossRef Medline

Mölle M, Born J (2011) Slow oscillations orchestrating fast oscillations and memory consolidation. Prog Brain Res 193:93-110. CrossRef Medline

Nishida M, Pearsall J, Buckner RL, Walker MP (2009) REM sleep, prefrontal theta, and the consolidation of human emotional memory. Cereb Cortex 19:1158-1166. CrossRef Medline

O'Neill J, Pleydell-Bouverie B, Dupret D, Csicsvari J (2010) Play it again: reactivation of waking experience and memory. Trends Neurosci 33:220 229. CrossRef Medline

Oudiette D, Paller KA (2013) Upgrading the sleeping brain with targeted memory reactivation. Trends Cogn Sci 17:142-149. CrossRef Medline

Oudiette D, Constantinescu I, Leclair-Visonneau L, Vidailhet M, Schwartz S, Arnulf I (2011) Evidence for the re-enactment of a recently learned behavior during sleepwalking. PLoS One 6:e18056. CrossRef Medline

Paller KA (1997) Consolidating dispersed neocortical memories: the missing link in amnesia. Memory 5:73-88. CrossRef Medline

Paller KA (2009) Memory consolidation: systems. In: Encyclopedia of neuroscience (Squire LR, ed), pp 741-749. Oxford: Academic.

Peigneux P, Laureys S, Fuchs S, Collette F, Perrin F, Reggers J, Phillips C, Degueldre C, Del Fiore G, Aerts J, Luxen A, Maquet P (2004) Are spatial memories strengthened in the human hippocampus during slow wave sleep? Neuron 44:535-545. CrossRef Medline

Peyrache A, Khamassi M, Benchenane K, Wiener SI, Battaglia FP (2009) Replay of rule-learning related neural patterns in the prefrontal cortex during sleep. Nat Neurosci 12:919-926. CrossRef Medline

Rasch B, Büchel C, Gais S, Born J (2007) Odor cues during slow-wave sleep prompt declarative memory consolidation. Science 315:1426-1429. CrossRef Medline

Rauchs G, Feyers D, Landeau B, Bastin C, Luxen A, Maquet P, Collette F (2011) Sleep contributes to the strengthening of some memories over others, depending on hippocampal activity at learning. J Neurosci 31: 2563-2568. CrossRef Medline

Rudoy JD, Voss JL, Westerberg CE, Paller KA (2009) Strengthening individual memories by reactivating them during sleep. Science 326:1079. CrossRef Medline

Saletin JM, Walker MP (2012) Nocturnal mnemonics: sleep and hippocampal memory processing. Front Neurol 3:59. CrossRef Medline

Saletin JM, Goldstein AN, Walker MP (2011) The role of sleep in directed forgetting and remembering of human memories. Cereb Cortex 21:25342541. CrossRef Medline

Singer AC, Frank LM (2009) Rewarded outcomes enhance reactivation of experience in the hippocampus. Neuron 64:910-921. CrossRef Medline

Sterpenich V, Albouy G, Darsaud A, Schmidt C, Vandewalle G, Dang Vu TT, Desseilles M, Phillips C, Degueldre C, Balteau E, Collette F, Luxen A, Maquet P (2009) Sleep promotes the neural reorganization of remote emotional memory. J Neurosci 29:5143-5152. CrossRef Medline 
Stickgold R (2005) Sleep-dependent memory consolidation. Nature 437: 1272-1278. CrossRef Medline

Tononi G, Cirelli C (2006) Sleep function and synaptic homeostasis. Sleep Med Rev 10:49-62. CrossRef Medline

van Dongen EV, Thielen JW, Takashima A, Barth M, Fernández G (2012) Sleep supports selective retention of associative memories based on relevance for future utilization. PLoS One 7:e43426. CrossRef Medline
Wagner U, Gais S, Haider H, Verleger R, Born J (2004) Sleep inspires insight. Nature 427:352-355. CrossRef Medline

Wilhelm I, Diekelmann S, Molzow I, Ayoub A, Mölle M, Born J (2011) Sleep selectively enhances memory expected to be of future relevance. J Neurosci 31:1563-1569. CrossRef Medline

Wilson MA, McNaughton BL (1994) Reactivation of hippocampal ensemble memories during sleep. Science 265:676-679. CrossRef Medline 